\title{
Explain the Basic Issues About Control of Corrupt Crimes in the View of Big Data
}

\author{
Yuehong $\mathrm{Wu}^{1}$ \\ The college of political and law, Guangdong University of Technology, Guangzhou, 510520, China; \\ julia66886@163.com
}

Keywords: Crime big data; corruption crime; prevention and control; function

\begin{abstract}
Big Data contains the law of social development and criminal governance, and how to prevent and control corruption crime to adapt to the tide of big data is the key to carry out the management of the number in crime prevention and control. In this regard, our country should pay attention to the issue of "big data crime", from the grasp of the concept and characteristics of big data, the basic problems such as the function of prevention and control of corruption in the interpretation of big data, through the precise crime prevention and control areas, crime for the big data era The upgrading of governance mode opens the way for evolution. As a tactical extension of the daily management strategy, corruption prevention and control is put forward to solve the "shortcomings problem" of corruption crime governance. Under the organic integration of "manpower + science and technology" and "traditional + modern" governance technology, Crime, crime of corruption, prevention of corruption crime application performance.
\end{abstract}

\section{Introduction}

Chinese society is entering the "risk society" as described by German sociologist Professor Beck, with the characteristics of modernization, industrialization and opening up. The artificial logic of uncertainty and the split status of social relations have brought difficulties to crime prevention and control. Corruption crime has long been the focus of social governance and criminal crime research. Most governments in the world regard the prevention and control of corruption as a headache. The process of informatization makes the social development trend contain the characteristics of big data. The use of technologies such as mobile media, social networks and mobile payment and the explosion of data and information have brought society from the IT era to the Data Technology (DT) era. ${ }^{1}$ Before the 18th National Congress of the Communist Party of China, the government adopted a formal policy of "fighting mainly and prevention supplemented". The 18th CPC Congress found that corruption, punishing corruption and preventing corruption are linked with " "Criminal policy is equally important, and then the academic research on the prevention and control of corruption crimes is developing rapidly. Today's era is the era of big data such as Internet + , artificial intelligence and cloud computing. All countries in the world are actively integrating into the big data wave. China released the "Action Plan for Big Data Development" in 2015. At the "2017 World Telecommunication and Information Society Day" conference held on May 17, 2017, relevant officials from the State Ministry of Industry and Information Technology (MIIT) said that China will build a nationwide big data center. ${ }^{2}$ It can be said that the full use of big data in all walks of life in various countries of the world has achieved initial success. Under the big data technologies and concepts, big data is used to solve the current problem of corruption prevention and control in our

\footnotetext{
${ }^{1}$ Yuehong $\mathrm{Wu}$,Guangdong University of Technology Institute of politics and law teacher, postdoctoral researcher, research direction: litigation law, Hong Kong and Macao basic law, criminal

${ }^{1}$ Xu Jihua, Feng Qina, Chen Zhenru: "Wisdom Government ----- big data era of governance," CITIC Publishing House 2014 edition.

${ }^{2}$ Ministry of Industry and Information: "China will build a national integrated big data center", set forth at http://news.163.com/17/0517/19/CKLO3JBM00018AOQ.html, accessed on May 18, 2017.
} 
country and improve the economic and social benefits of prevention and control of corruption crimes in our country It is very important. Based on this, in the era of big data, intelligence research, risk warning and information analysis technologies may provide new ideas for the scientific prevention and control of corruption crimes in China.

The "13th Five-Year Plan" proposal adopted by the Fifth Plenary Session of the 18th CPC Central Committee put forward the proposal of "implementing the strategy of national big data and promoting open sharing of data resources" to elevate big data to unprecedented heights. In 2017, the National Attorney General's Conference proposed that in order to comply with the development trend of the information era, take the construction of e-government as a starting point and take the application of big data as the guide, and gradually realize the exchange and sharing of information resources with other political and legal departments and relevant administrative departments, Pay close attention to upgrade and perfect the unified business application system, comprehensively promote the construction of national procuratorial big data center, and accelerate the construction of intelligent quarantine "; On May 17, 2017, the Supreme People's Procuratorate issued the" Guidelines for Large-scaly Proceedings (2017-2020) " , Analyzed the background and current situation of procuratorial big data construction and formulated the list of key tasks, which laid a solid foundation for the dataization direction of procuratorial work in the future.

\section{The Concept and Characteristics of Big Data}

\subsection{The Concept of The Big Data}

The definition of big data, the academic community divergent opinions. In the international community, Gartner, a world-renowned IT research and consulting firm, said: "Big data is a diverse, massive and growth-oriented information asset that generates strong decision-making power based on new processing paradigms , Insight and process optimization capabilities. " ${ }^{3}$ Nomura Research Institute, a well-known think-tank in Japan, said: "Big data is a collection of large amounts of data and information resources that are difficult to manage using the existing general technologies." According to Forrester, a well-known consulting firm in the United States, "Big data is to fill There is a gulf between information and your capabilities, turning information into insight into your business. " ${ }^{4}$ Visible, the international community of scholars on the definition of big data, though different, but all stressed the big data contains information resources, complex, can be mined and other factors. In China, some scholars think: "Big data refers to the data combination that can not be perceived, acquired, managed, processed and served by traditional information technology and software and hardware tools within tolerable time." ${ }^{5}$ "Big data, or huge amounts of data, refers to massive, high-growth, and diverse information assets that require new processing models for greater decision-making, insight, and process optimization." ${ }^{6}$ The so-called big data, refers to the data explosion in the era of massive data mining, analysis, and for the use of technological innovation, which hosts the platform is mainly focused on the Internet platform. ${ }^{7}$ Can be seen that although the definition of big data domestic scholars have different opinions, but also mentioned the large capacity, pending processing, information resources and other factors.

Big data, as a new type of technology architecture, is a new trend in the development of modern information technology. This paper argues that big data refers to a diverse, massive and highly-growth information asset over a period of time that is based on a new processing paradigm that

\footnotetext{
${ }^{3}$ Zhang Yuhong: "taste big data", Peking University Press, 2016 edition, the first 109 pages.

${ }^{4}$ Nicole Laskowski.The big data architecture dilemma for

CIOs.TechTarget.http//searchcio.techtarget.com/feature/The-big-data-architecture-dilemma-for-CIOs.2014-08

${ }^{5}$ Li Guojie, Cheng Xueqi: "Big Data Research: Major Strategic Areas for Science, Technology and Economic Development in the Future ------- Present Status and Scientific Considerations of Big Data", Proceedings of the CAS, 2012, No.6.

${ }^{6}$ Big Data, at https://baike.so.com/doc/5374131-5610149.html, November 4, 2013.

${ }^{7}$ Wang Fang: "Prevention and Control Countermeasures of Internet Financial Crimes in Big Data Era", in "Time Finance", No. 1, 2016.
} 
is vast in scope and generates strong decision-making power, insight, and process optimization capabilities As well as tremendous value of pending information.

\subsection{The Features of The Big Data}

Based on the above analysis, it can be concluded that big data has the following characteristics:1. Big data is a data set. Big data is a set of data with large data capacity, multiple data types, fast growth and low value density. Large data capacity, that is, the magnitude of data has risen from GB to TB, PB and even $\mathrm{ZB}$, can be called massive, huge or even excessive, and is still continuing to explode; ${ }^{8}$ The data category is more data information from the original simple numerical, character and text to web pages, pictures, video, image and location information, such as semi-structured and unstructured data types; rapid growth that the timeliness of big data requirements Data processing can be done in real-time and fast. To achieve this goal, the hardware platform required to be used can also be updated synchronously, and technologies such as distributed computing, parallel computing, software engineering and artificial intelligence are applied to it. ${ }^{9}$ The low value density means that the Internet is full of repetitive and fake information, often valuable information is more scattered and less dense. 2. Big data is a new generation of information system architecture and technology. Big Data is a next-generation information system architecture and technology that enables the collection, storage, and correlation analysis of large numbers, diverse sources and diverse formats of data. 3. Big data represents a new way of thinking. Big data represents a new way of thinking ----- Big data thinking is a powerful cognitive world that can help people discover new knowledge, create new value, improve new abilities and form new formats from vast amounts of data The world's ability. ${ }^{10}$

\section{The Function of The Big Data in The Prevention and Control of Corruption Crimes}

\subsection{Enhance the Prevention and Control of Corruption Crime Initiative and Rigor}

Big data emphasizes data integrity and miscellaneous, and using big data technology can bring the case closer to the truth. In the process of prevention and control of corruption crime, from the superiority of big data analysis and forecasting, big data analysis and forecasting technology is introduced into the prevention and control of corruption crimes. Using big data technology to integrate information resources and optimize the information resource utilization chain can overcome the hierarchical, Fragmented and regional administration mode may bring the impact of "administrative fragmentation", to achieve "point to point, menu-based" management and services. Especially in the prevention and control of corruption crimes, big data technology will play a crucial role. Through data monitoring, mining and analysis, we can find the anomalies and risk factors in corruption crimes in time, predict the trends and probabilities of corruption crimes, remind us of "what is happening" and guide the relevant actors to make prevention and control strategies and self-protection Measures to further reduce the risk of failure of information reporting, prevent and avoid major corruption crimes, and ultimately enhance the prevention and control of corruption crimes initiative and rigor! Relevant agencies and departments to deal with corruption crimes should use big data technology as a major prevention and control tool to achieve the maximum integration and sharing of social information resources among government departments with population-based information and information as the main body, and use this technology to improve the " Abnormal "attention, timely prediction, early warning of corruption crimes.

\subsection{Increase The Accuracy and Effectiveness of Crime Prevention and Combating Corruption}

Prediction is a core element of big data technology, and efficiency is one of the features of big data technology. At present, big data is mainly used to (1) report corruption offenses with traditional evidence; (2) enhance the transparency of government operation; (3) build a database of corruption

\footnotetext{
${ }^{8}$ Duan bamboo, Tian Hong editor: "big data foundation and management", Tsinghua University Press, 2016 edition.

${ }^{9}$ Duan bamboo, Tian Hong editor: "big data foundation and management", Tsinghua University Press, 2016 edition.

${ }^{10}$ See Zhiguang Shan: "' on the promotion of big data development action outline "interpretation," URL:

http://news.xinhuanet.com/info/2015-09/17/c_134632376.htm
} 
crimes; and (4) recover the stolen goods from big data. ${ }^{11}$ In the prevention and control of corruption crimes, the use of big data thinking and big data tools, the introduction of corruption crime spatiotemporal analysis system and hotspot analysis and prediction technology, you can address, space and other static factors and character, event information and other dynamic factors, the massive data "Instant" into intelligence products, changing the advantages of lag analysis of traditional criminal offenses, dynamically grasping the characteristics and trends of the law of corruption crimes in terms of quality, quantity, time and space, and enriching the means of detecting and solving crimes; meanwhile, using the thinking of big data to analyze the traditional situation Store outdated information into available information. Through the instantaneous and dynamic analysis and prediction of multiple corruption crimes, the relevant time and space information can be intelligently associated and dynamically cross-checked so as to quickly lock the suspects, Providing a new way of thinking on issues related to the handling of cases and people, improving the accuracy of cracking down on and preventing corruption crimes, and achieving the goal of "breaking the big case more quickly and breaking more small cases and controlling the crime better." For example, an instant analysis of the amount involved in a crime of embezzlement and bribery can accurately predict corrupt crimes such as corruption and bribery.

\subsection{To Help Punish Corruption Crimes, Corruption Prevention and Control to Enhance the Effectiveness of Corruption}

Technology is a double-edged sword that can be used illegally by criminals when it is convenient for people to produce and live. In the field of corruption crime, it is manifested in the increasingly concealed and intelligent means of crime, the difficulty of finding criminal clues, the difficulty in collecting evidence of crime, and the large number of criminal blacks (that is, the number of corruption crimes that have been implemented but have not yet been investigated and dealt with by organs). Big data provides a new perspective to solve these problems. Due to the data recording and restoring the world, the crime of corruption can be transformed into recordable and analytic data, dispersed in a third party. By mining the massive related information, the information associated with the crime can be found, and the crime at that time can be traced back and restored. Criminal clues and their accurate analysis. However, controlling the black number of corruption crimes is the core of preventing and controlling corruption crime fundamentally. Because of the existence of black crime of corruption, the criminals are lucky, and subjectively believe that crime and punishment do not have the necessary causal link, even if they are punished It is only a possibility, not to mention penalties are not timely. The principle of the profitability of crime determines the probability that the suspect will be repeatedly weighed before the implementation of the corruption crime to judge his behavior may be found. If the probability is small, it will strengthen its determination to commit crimes; on the contrary, it will reduce its tendency to commit crimes. ${ }^{12}$ Therefore, big data technologies can help punish corruption crimes.

In the era of big data, everyone creates data for their own actions and also contacts other people's behavior data due to specific social roles. The data on the behavior of corrupt officials include precisely the data that the corruption prevention and control authorities find it hard to grasp. The use of the Internet, cloud computing, and artificial intelligence in turn allows each individual to express their opinions freely through virtual spaces. The public's high concern about corruption crimes and zero tolerance have stimulated citizens' willingness to participate in the prevention and control of corruption crimes, to a certain extent, enhanced the effectiveness of prevention and control of corruption crimes. Performance in three aspects: (1) prevention and control of a wide range of subjects. The most important thing for anti-corruption is public participation. The public spread their own corrupt information through new technologies such as the Internet. This has caused the Discipline Inspection Commission and procuratorate departments to pay attention to them and even

\footnotetext{
${ }^{11}$ Zhang Ling and Guo Yan, eds., Crime Prevention and Control under the Age of Big Data, Proceedings of the Annual Meeting of China Society of Criminology (2017), China Procurator's Publishing House 2017Edition, p. 834.

${ }^{12}$ Cheng Hong: "The Transformation of the Investigation Mode of Anti-Corruption in the Background of Big Data", China Prosecutor, No. 2, 2015.
} 
investigate them. (2) There are many means of prevention and control. Specific cases of corruption crimes will spread through the media and circle of friends through unspecified new technological means so as to give all those who may be involved in crimes a warning and thus dare not defy them; (3) to follow up the prevention of corruption crimes Into the forecast in advance. According to the big data thinking mode and processing method, through collecting and analyzing big data, the factors associated with the crime of corruption are identified. If the factor appears, it indicates that the corruption crime has occurred or is about to occur, and targeted prevention measures can be taken.

\subsection{Conducive to Improving The Decision-making Authority of The Scientific, Guiding and The Development of Personal Corruption Prevention and Control Policies}

The nature of big data is a way of using information resources, which has a profound and extensive impact on human society. Big data has the following performance in the area of corruption crime prevention: (1) data recording world; (2) data restoration behavior; (3) data forecasting future. The use of big data methods can maximize the perfect symmetry of information to improve the level of scientific and democratic decision-making. Corrupt criminal decision-making departments and decision-makers should attach great importance to the use of corruption-related information resources, make full use of social and institutional (department) big data resources, "let the data speak" to improve the efficiency of decision-making and operational as the goal, establish and improve the judiciary Decision-making and operational processes, establish and improve an open and flat decision-making management system so that the macroeconomic decisions of the judiciary are based on as much data support as possible, rather than local factual and empirical judgments, and effectively improve the scientific decision- Reliability, objectivity. ${ }^{13}$ Such as the use of big data technology as much as possible to collect mass recommendations, from decision-making bodies and policy makers to "think their ideas and ideas" to the masses, netizens come up with ideas, policy makers from "ideas, ideas" change, to make more decisions Closely to reality, close to the masses, close to the grassroots level, so as to achieve the goal of "public opinion leads the prevention and control of corruption crimes".

The current prevention and control of corruption crimes essentially focus on the "remedial measures to make the best of one country and the right one", mainly focusing on the specific cases investigated and dealt with by anti-corruption departments, analyzing the loopholes in the system and putting it to the whole field for preventive education, To a certain industry, a certain post, a specific corruption risk of individual officials point, the effect is not good, but also poor. With the analysis of the data of the industries, posts and individuals and the combination of corruption crimes data, we can precisely draw the corruption risk chart of "industry, job and personal" in order to make different prevention and control policies according to different targets, To achieve the best prevention and control effect.

\section{Conclusions}

Humans have quietly entered the era of big data, the data itself does not add any value, its main performance is reflected in how to deal with, analyze and make use of these data. The use of big data to drive corruption crime governance decision-making for future corruption crime governance decision-making to achieve the scientific and technological possibilities, corruption crime prevention and control departments to comply with the development trend, seize the opportunities for development, the application of big data, relying on big data, data-driven decision- Let the data support anti-corruption, to achieve the best prevention and control of corruption crimes. Of course, while this technology brings about a great change of ideas, it also brings many problems such as privacy and infringement of personal information to the corruption crime governance itself. Therefore, it faces many disputes and questions. In any case, the original extensive prevention and control decision-making model of crime will inevitably shift towards a refined and scientific

\footnotetext{
${ }^{13}$ See Wang Qing and Jiang Ping, "Design and Construction of Metropolitan Big Data Police Cloud Computing Platform ------ Take Nanjing Public Security Big Data Police Cloud Computing Platform as an Example", "Police Technology", Issue 5, 2016 .
} 
decision-making model of criminal governance. The data sampling and analysis techniques of small samples will inevitably be replaced by data mining and intelligence research of big data replace. In the process, the risk of technology itself will be gradually overcome by the development and evolution of technology itself. The focus of future research should be on how to expand the application of big data technology and gradually develop its application value in the field of broader crime control and crime prediction

\section{Acknowledgments}

This work was financially supported by Yuehong Wu presided over the 2016 China Postdoctoral Science Foundation Program "Confession of Penalties and Penalties from the system of procedural control" (project number: 2016M602437); Guangdong Philosophy and Social Science Thirteen Five Year Plan 2017 disciplines co-construction project "big data era Under the Guangdong comprehensive governance according to law practice province "(project number: GD17XFX13) phase of the research results

\section{References}

[1] Cheng Hong: "The Transformation of the Investigation Mode of Anti-Corruption in the Background of Big Data", China Prosecutor, No. 2, 2015.

[2] Zhang Ling and Guo Yan, eds., Crime Prevention and Control under the Age of Big Data, Proceedings of the Annual Meeting of China Society of Criminology (2017), China Procurator's Publishing House 2017Edition, p. 834.

[3] Duan bamboo, Tian Hong editor: "big data foundation and management", Tsinghua University Press, 2016 edition.

[4] Li Guojie, Cheng Xueqi: "Big Data Research: Major Strategic Areas for Science, Technology and Economic Development in the Future ------- Present Status and Scientific Considerations of Big Data", Proceedings of the CAS, 2012, No.6.

[5] Zhang Yuhong: "taste big data", Peking University Press, 2016 edition, 109 p.

[6] Xu Jihua, Feng Qina, Chen Zhenru: "Wisdom Government ----- big data era of governance," CITIC Publishing House 2014 edition. 